\title{
Pengaruh Terpaan Iklan Billboard Lazada Versi Terbalik dan Promosi Word of Mouth Terhadap Tingkat Kesadaran Merek
}

\author{
Lazada" \\ Nico Putra, Widayatmoko
nico.915150037@stu.untar.ac.id,widayatmoko@fikom.untar.ac.id
}

Fakultas Ilmu Komunikasi Universitas Tarumanagara

\begin{abstract}
This study aims to know how the exposure of billboard advertising and word of mouth promotion activity can significantly give impact to brand awareness. The theory that used in this research is the theory of advertising, integrated marketing communication, word of mouth, and brand awareness. This study uses quantitative research approach with survey methods. The research technique used is non-probability sampling with purposive sampling approach with a total of 100 people as respondents. Data collection techniques is using questionnaires and literature studies. Techniques to test requirements analysis is using tests of validity, reliability, and multicollinearity. Data analysis is using multiple correlation coefficients, coefficient of determination, multiple linear regression analysis, $T$ test and $F$ test. The results of the multiple correlation coefficient test shows 0.624 which means a strong relationship between medium variables, while the coefficient of determination results is $38,9 \%$ brand awareness of Lazada is influenced by the exposure of billboard advertising and word of mouth promotion. The results of the T test of XI variable shows that Ha is rejected and $\mathrm{Ho}$ is accepted, means the exposure of Lazada's billboard advertising doesn't significantly give impact to brand awareness of Lazada. Meanwhile the T test of X2 variable shows that Ha is accepted, means word of mouth promotion is significantly give impact to brand awareness of Lazada. Based on the F test results it is known that Sig 0,000 < 0,05 then Ha is accepted, means that the exposure of Lazada's billboard advertising and word of mouth promotion simultaneously are significantly give impact to brand awareness of Lazada.
\end{abstract}

Keywords: The Exposure of Billboard Advertising, Word of Mouth Promotion, Brand Awareness

Abstrak

Penelitian ini bertujuan untuk mengetahui bagaimana terpaan iklan billboard dan kegiatan promosi word of mouth dapat berpengaruh terhadap tingkat kesadaran merek. Teori yang digunakan dalam penelitian ini adalah teori periklanan, komunikasi pemasaran terpadu, word of mouth, dan kesadaran merek. Penelitian ini menggunakan pendekatan kuantitatif dengan metode survei. Teknik penelitian yang digunakan adalah non-probability sampling dengan pendekatan purposive sampling dengan jumlah responden sebanyak 100 orang. Teknik pengumpulan data dilakukan dengan menggunakan kuesioner dan studi kepustakaan. Teknik untuk menguji keabsahan data dilakukan dengan menggunakan uji validitas, reliabilitas, dan uji multikolinearitas. Analisis data dilakukan dengan menggunakan koefisien korelasi berganda, koefisien determinasi, analisis regresi linier berganda, uji T dan uji F. Hasil dari uji koefisien korelasi berganda menunjukkan angka 0,624 yang artinya memiliki hubungan antar variabel yang kuat, sedangkan pada koefisien determinasi didapatkan hasil sebesar 38,9\% tingkat kesadaran merek Lazada dipengaruhi oleh terpaan iklan billboard Lazada dan promosi word of mouth. Hasil uji T variabel X1 diketahui bahwa Ha ditolak dan Ho diterima, artinya terpaan iklan billboard Lazada tidak berpengaruh secara signifikan terhadap tingkat 
kesadaran merek Lazada. Sedangkan hasil uji T variabel X2 diketahui bahwa Ha diterima, artinya promosi word of mouth berpengaruh secara signifikan terhadap tingkat kesadaran merek Lazada. Berdasarkan hasil uji F diketahui Sig 0,000 < 0,05 maka Ha diterima, artinya variabel terpaan iklan billboard Lazada dan promosi word of mouth secara bersamaan berpengaruh secara signifikan terhadap tingkat kesadaran merek Lazada.

Kata Kunci: Terpaan Iklan Billboard, Promosi Word of Mouth, Tingkat Kesadaran Merek

\section{Pendahuluan}

Perkembangan teknologi informasi dan komunikasi pada saat ini membawa peradaban umat manusia ke zaman yang serba praktis, dan banyak mengandalkan media digital. Salah satu dampak dari perkembangan internet dan media digital yang sangat pesat ini, adalah munculnya peluang baru di dunia bisnis, yakni adanya media baru untuk berbelanja secara online yang pada zaman sekarang sering disebut juga dengan e-commerce. E-commerce menjadi salah satu media yang sangat digemari pada zaman sekarang, karena kemudahannya untuk berbelanja hanya dengan mengandalkan media digital, tanpa perlu ada pertemuan antara penjual dengan pembeli.

Perkembangan belanja online ini pun membuat adanya persaingan yang cukup ketat di antara berbagai e-commerce yang ada, dan salah satu e-commerce yang turut meramaikan persaingan tersebut adalah Lazada. Lazada merupakan e-commerce yang diluncurkan pada tahun 2012, dan merupakan salah satu destinasi belanja dan berjualan online nomor satu di Asia Tenggara. Lazada telah hadir di Indonesia, Malaysia, Filipina, Singapura, Thailand dan Vietnam. Berdasarkan data Asean Up, hingga Maret 2018, Lazada merupakan e-commerce nomor 1 dari segi estimasi kunjungan website bulanan di Indonesia, diikuti dengan beberapa e-commerce ternama lainnya di Indonesia.

Sama halnya dengan berbagai bisnis pada umumnya, e-commerce juga selalu berusaha untuk melakukan berbagai jenis promosi dan komunikasi pemasaran, untuk menarik banyak peminat yang mau untuk menggunakan produk tersebut. Selain itu, berbagai promosi tersebut juga bertujuan untuk menimbulkan kesadaran khalayak akan merek tersebut. Dari sekian banyak bentuk promosi, salah satu bentuk promosi yang paling dikenal dan banyak dibahas orang adalah iklan, hal ini disebabkan oleh daya jangkaunya yang luas. Iklan juga dapat didefinisikan sebagai salah satu bentuk komunikasi non-personal mengenai suatu organisasi, produk, jada, maupun ide yang dibayar oleh sponsor yang diketahui. (Morrisan, 2010:17-18)

Word of mouth saat ini juga menjadi variabel yang penting dalam memasarkan suatu produk, dan juga dalam membangun kesadaran merek. Trusov et al (2009) menyatakan strategi word of mouth merupakan salah satu strategi yang sangat menarik karena pada dasarnya, pada strategi ini, terdapat pembiayaan yang murah dan juga komunikasi antar individu yang cepat, terutama melalui perkembangan internet dan sosial media.

Setiap merek pastinya akan berusaha untuk membuat komunikasi pemasaran yang unik, dan menarik bagi khalayak, tidak terkecuali dengan Lazada. Pada akhir tahun 2017, Lazada melakukan komunikasi pemasaran melalui iklan billboard yang cukup unik, dengan secara sengaja memasang iklan tersebut dengan posisi terbalik. Melalui iklan tersebut, Lazada telah melakukan suatu kegiatan iklan yang cukup efektif. 
Selain itu, Lazada juga gencar dalam melakukan promosi word of mouth, hal ini tercermin dari pengakuan Achmad Alkatiri selaku CMO Lazada Indonesia yang mengatakan bahwa konsumen sekarang ini sering merujuk pada rekomendasi teman atau kerabatnya ketika akan melakukan transaksi, Lazada sendiri melakukan promosi word of mouth nya melalui berbagai kegiatan melalui media sosial seperti kampanye, dan dengan meningkatkan Key Opinion Leader (KOL) dalam meningkatkan kedekatan dengan konsumen.

Mohammad Pambudi (2016) menyatakan bahwa Brand awareness atau kesadaran merek sebenanya adalah kemampuan daya ingat konsumen terhadap suatu merek yang telah melekat dalam pikiran konsumen akan suatu produk tertentu. Kesadaran merek ini pada umumnya berusaha untuk dibangun oleh suatu merek dalam benak konsumen, melalui berbagai kegiatan promosi.

Berdasarkan latar belakang yang telah diuraikan di atas, penulis berusaha untuk mengetahui apakah terdapat pengaruh dari terpaan iklan melalui media billboard serta promosi word of mouth yang dilakukan Lazada terhadap tingkat kesadaran merek. Maka, penulis mengajukan penelitian berjudul "Pengaruh Terpaan Iklan Billboard Lazada Versi "Terbalik" Dan Promosi Word Of Mouth Terhadap Tingkat Kesadaran Merek Lazada".

Berdasarkan latar belakang tersebut, penulis merumuskan masalah dalam penelitian ini yaitu apakah terpaan iklan billboard Lazada versi "terbalik" berpengaruh terhadap tingkat kesadaran merek Lazada, apakah promosi word of mouth berpengaruh terhadap tingkat kesadaran merek Lazada, dan apakah terpaan iklan billboard Lazada versi "terbalik" dan promosi word of mouth berpengaruh terhadap tingkat kesadaran merek Lazada.

Tujuan dari penelitian ini adalah untuk mengetahui pengaruh terpaan iklan billboard versi "terbalik" terhadap tingkat kesadaran merek Lazada, untuk mengetahui pengaruh promosi word of mouth terhadap tingkat kesadaran merek Lazada, dan untuk mengetahui pengaruh terpaan iklan billboard versi "terbalik" dan promosi word of mouth terhadap tingkat kesadaran merek Lazada.

\section{Metode Penelitian}

Pendekatan penelitian yang penulis gunakan dalam penelitian ini adalah pendekatan penelitian kuantitatif. Pendekatan kuantitatif menurut Sugiyono (2011:14) merupakan metode penelitian yang berdasarkan pada filsafat positivism, dan biasanya digunakan dalam meneliti populasi atau sampel tertentu. Dalam penelitian ini, peneliti memilih pendekatan penelitian kuantitatif dengan metode survei. Menurut Nazir (2011:56), metode survei sendiri adalah metode analisis yang diadakan untuk memperoleh fakta-fakta dari gejala yang ada dan mencari informasi secara faktual, baik tentang berbagai institusi maupun kelompok tertentu

Populasi yang digunakan dalam penelitian ini adalah seluruh pengguna Lazada Indonesia. Berdasarkan data dari iPrice, jumlah pengunjung Lazada pada pertengahan tahun 2018 bersikar di angka 50 juta pengunjung. Dalam penelitian ini, peneliti menetapkan jumlah sampel sebanyak 100 responden, dengan kriteria sampel sudah pernah menggunakan Lazada. Teknik pengambilan sampel pada penelitian ini didasarkan pada metode non-probability sampling dengan menggunakan pendekatan purposive sampling. Data dikumpulkan dengan menyebarkan kuesioner yang menggunakan skala likert. Data primer dalam penelitian ini diperoleh melalui penyebaran kuesioner. Sedangkan data sekunder didapat melalui studi pustaka dan 
internet. Untuk mengetahui keabsahan data dalam penelitian ini, penulis melakukan uji validitas, uji reliabilitas, dan uji multikolinearitas. Sedangkan untuk pengolahan data dalam penelitian ini, penulis melakukan uji koefisien korelasi berganda, uji koefisien determinasi, uji regresi linear berganda, uji T dan uji F.

Hipotesis dalam penelitian ini adalah sebagai berikut:

$\left(\mathrm{X}_{1} \mathrm{Y}\right)$

Ha: Terdapat pengaruh antara terpaan iklan billboard Lazada versi "terbalik" (X1) terhadap tingkat kesadaran merek Lazada (Y).

Ho: Tidak terdapat pengaruh antara terpaan iklan billboard Lazada versi "terbalik" (X1) terhadap tingkat kesadaran merek Lazada (Y). $\left(\mathrm{X}_{2} \mathrm{Y}\right)$

Ha: Terdapat pengaruh antara promosi word of mouth (X2) terhadap tingkat kesadaran merek Lazada (Y).

Ho: Tidak terdapat pengaruh antara promosi word of mouth (X2) terhadap tingkat kesadaran merek Lazada (Y).

$\left(\mathrm{X}_{1} \mathrm{X}_{2} \mathrm{Y}\right)$

Ha: Terdapat pengaruh antara terpaan iklan billboard Lazada versi "terbalik" (X1) dan promosi word of mouth (X2) terhadap tingkat kesadaran merek Lazada (Y).

Ho: Tidak terdapat pengaruh antara terpaan iklan billboard Lazada versi "terbalik" (X1) dan promosi word of mouth (X2) terhadap tingkat kesadaran merek Lazada (Y).

\section{Hasil Temuan dan Diskusi}

Dari 100 responden yang menjadi sampel penelitian, mayoritas responden adalah perempuan. Berdasarkan usia, mayoritas responden berusia 21-25 tahun, dengan mayoritas berdomisili Jakarta, serta berstatus D1/S1.

Uji Keabsahan Data

Dari data 100 responden, penulis melakukan uji validitas, uji reliabilitas, dan uji multikolinearitas untuk menguji butir-butir pernyataan yang terdapat pada kuesioner.

Uji Validitas

Tabel 1. Uji Validitas

\begin{tabular}{cccc}
\hline $\mathbf{X}_{\mathbf{1}}$ & $\begin{array}{c}\text { Corrected Item }- \text { Total } \\
\text { Correlation }\end{array}$ & Nilai Patokan & Keterangan \\
\hline P1 & 0.630 & 0,361 & Valid \\
P2 & 0.799 & 0,361 & Valid \\
P3 & 0.824 & 0,361 & Valid \\
P4 & 0.737 & 0,361 & Valid \\
P5 & 0.722 & 0,361 & Valid \\
P6 & 0.778 & 0,361 & Valid \\
P7 & 0.814 & 0,361 & Valid \\
P8 & 0.850 & 0,361 & Valid \\
P9 & 0.865 & 0,361 & Valid \\
P10 & 0.812 & 0,361 & Valid \\
P11 & 0.665 & 0,361 & Valid \\
P12 & 0.689 & 0,361 & Valid
\end{tabular}


Nico Putra, Widayatmoko: Pengaruh Terpaan Iklan Billboard Lazada Versi "Terbalik" dan Promosi Word of Mouth Terhadap Tingkat Kesadaran Merek Lazada"

\begin{tabular}{llll} 
P13 & 0.715 & 0,361 & Valid \\
P14 & 0.564 & 0,361 & Valid \\
P15 & 0.695 & 0,361 & Valid \\
P16 & 0.715 & 0,361 & Valid \\
\hline
\end{tabular}

(Sumber: SPSS)

\section{Uji Reliabilitas X1}

Setelah melakukan uji SPSS, penulis mendapatkan hasil 0,798 untuk pernyataan X1 (Terpaan Iklan Billboard). Pernyataan tersebut dinyatakan reliabel karena nilai Cronbach's Alpha 0,798 > 0,7

Uji Reliabilitas X2

Setelah melakukan uji SPSS, penulis mendapatkan hasil 0,800 untuk pernyataan X1 (Terpaan Iklan Billboard). Pernyataan tersebut dinyatakan reliabel karena nilai Cronbach's Alpha 0,800>0,7

\section{Uji Reliabilitas Y}

Setelah melakukan uji SPSS, penulis mendapatkan hasil 0,768 untuk pernyataan X1 (Terpaan Iklan Billboard). Pernyataan tersebut dinyatakan reliabel karena nilai Cronbach's Alpha 0,768>0,7

Uji Multikolinearitas

Setelah diuji menggunakan SPSS, penulis mendapatkan hasil bahwa tingkat tolerance sebesar 0,842 yang berarti lebih besar dari 0,10 yang menunjukkan tidak multikolinearitas dan VIF sebesar 1,188 yang berarti lebih kecil dari 10 menunjukkan tidak terjadinya multikolinearitas.

Analisis Data:

Uji koefisien korelasi berganda

\section{Gambar 1. Uji Koefisien Korelasi Berganda (Sumber: SPSS)}

\begin{tabular}{|l|l|l|c|c|}
\hline Model & $\mathrm{R}$ & $\mathrm{R}$ Square & $\begin{array}{c}\text { Adjusted R } \\
\text { Square }\end{array}$ & $\begin{array}{c}\text { Std. Error of } \\
\text { the Estimate }\end{array}$ \\
\hline 1 & $.624^{\mathrm{a}}$ & .389 & .376 & 3.12252 \\
\hline
\end{tabular}
a. Predictors: (Constant) Word of mouth, Terpaan Iklan
b. Dependent Variable: Kesadaran merek

Setelah diuji menggunakan SPSS, penulis mendapatkan hasil bahwa koefisien korelasi (r) dari variabel X dan Y dalam penelitian ini sebesar 0,624. Nilai $r$ sebesar 0,624 menunjukkan hubungan antara terpaan iklan billboard (X1) dan promosi word of mouth (X2) dengan tingkat kesadaran merek (Y) adalah kuat (Sugiyono, 2017:231).

Koefisien determinasi

Berdasarkan Gambar 1, penulis mendapatkan hasil nilai koefisien determinasi dengan melihat angka yang ada pada $\mathrm{R}$ square. Hasil dari $\mathrm{R}$ square adalah 0,389 sama dengan 38,9\% yang artinya variabel $\mathrm{X}$ dapat menjelaskan variabel $\mathrm{Y}$ sebesar $38,9 \%$ dan sisanya $61,1 \%$ dipengaruhi oleh variabel lain.

Analisis Regresi Linier Berganda 


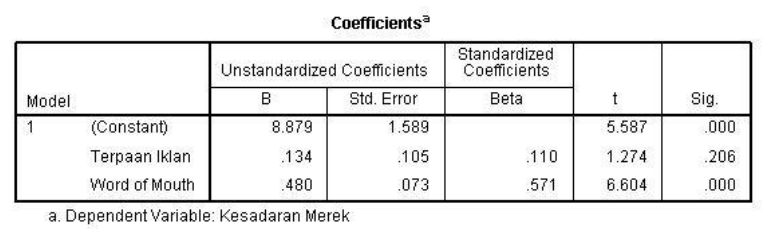

\section{Gambar 2. Analisis Regresi Linear Berganda dan Uji T (Sumber: SPSS)}

$$
\mathrm{Y}=\alpha+\mathrm{b}_{1} \mathrm{X}_{1}+\mathrm{b}_{2} \mathrm{X}_{2}
$$

Setelah diuji menggunakan SPSS, penulis mendapatkan hasil nilai sebesar 8,879 menyatakan konstanta dari fungsi regresi yang menunjukkan bahwa jika tidak ada kenaikan variabel X1 (terpaan iklan billboard) dan X2 (promosi word of mouth), maka variabel Y (tingkat kesadaran merek) akan mencapai 8,879. Setiap ada penambahan 1 angka atau perubahan variabel X1 (terpaan iklan billboard), maka variabel Y (tingkat kesadaran merek) akan mengalami peningkatan sebesar 0,134. Setiap ada penambahan 1 angka atau perubahan variabel X2 (promosi word of mouth), maka variabel Y (tingkat kesadaran merek) akan mengalami peningkatan sebesar 0,480 .

\section{Uji T}

Setelah dilakukan uji SPSS, penulis mendapatkan hasil uji T terhadap X1 bahwa nilai sig > $\alpha$ yaitu 0,206 > 0,05 maka Ho diterima, maka terpaan iklan billboard tidak berpengaruh signifikan terhadap tingkat kesadaran merek Lazada. Hasil uji T terhadap X2 menunjukkan bahwa nilai sig < a yaitu $0,000<0,05$ maka Ha diterima, maka promosi word of mouth berpengaruh signifikan terhadap tingkat kesadaran merek Lazada.

Uji F

Gambar 3. Uji F

ANOVA $^{\mathrm{b}}$

\begin{tabular}{|c|c|c|c|c|c|c|}
\hline \multicolumn{2}{|c|}{ Model } & $\begin{array}{c}\text { Sum of } \\
\text { Squares }\end{array}$ & df & Mean Square & $\mathrm{F}$ & Sig. \\
\hline \multirow[t]{3}{*}{1} & Regression & 830.754 & 2 & 415.377 & 24.538 & $.000^{\mathrm{a}}$ \\
\hline & Residual & 1641.996 & 97 & 16.928 & & \\
\hline & Total & 2472.750 & 99 & & & \\
\hline
\end{tabular}

(Sumber: SPSS)

Setelah diuji menggunakan SPSS, penulis mendapatkan nilai sig $<0,05$ yaitu $0,000<0,05$. Hal ini dapat dikatakan hasil uji $\mathrm{F}$ adalah Ho ditolak dan Ha diterima, artinya variabel X1 dan variabel X2 secara bersama-sama mempengaruhi variabel $\mathrm{Y}$, maka terdapat pengaruh terpaan iklan billboard dan promosi word of mouth secara bersama-sama terhadap tingkat kesadaran merek Lazada. 
Nico Putra, Widayatmoko: Pengaruh Terpaan Iklan Billboard Lazada Versi "Terbalik" dan Promosi Word of Mouth Terhadap Tingkat Kesadaran Merek Lazada"

\section{Simpulan}

Hasil pengujian hipotesis pertama secara parsial menunjukkan bahwa terpaan iklan billboard Lazada versi "terbalik" tidak memberikan pengaruh yang signifikan terhadap tingkat kesadaran merek Lazada, yang dilihat dari hasil uji $\mathrm{T}$ yang menunjukkan bahwa nilai signifikan 0,206 > 0,05. Indikator yang memberikan pengaruh paling signifikan adalah atensi, sedangkan yang kurang memberikan pengaruh yang signifikan adalah frekuensi.

Hasil pengujian hipotesis kedua secara parsial menunjukkan bahwa promosi word of mouth memberikan pengaruh yang signifikan terhadap tingkat kesadaran merek Lazada, yang dilihat dari hasil uji $\mathrm{T}$ yang menunjukkan bahwa nilai signifikan $0,000<0,05$. Indikator yang paling memberikan pengaruh yang signifikan adalah cerita positif, sedangkan yang kurang memberikan pengaruh signifikan adalah ajakan teman.

Hasil pengujian hipotesis ketiga secara simultan menunjukkan bahwa terpaan iklan billboard Lazada dan promosi word of mouth secara bersama-sama memberikan pengaruh yang signifikan terhadap tingkat kesadaran merek Lazada, yang dilihat dari hasil uji F yang menunjukkan bahwa nilai signifikan 0,000<0,05. Terpaan iklan billboard Lazada dan promosi word of mouth membawa tingkat kesadaran merek Lazada ke tahap Brand Recall.

Berdasarkan pada simpulan hasil penelitian yang telah dilakukan oleh peneliti, terdapat beberapa hal yang dapat disarankan oleh penulis, diantaranya:

1. Bagi peneliti yang akan melakukan penelitian dengan topik serupa dengan penelitian ini, terdapat banyak hal yang dapat digali lebih dalam lagi, mulai dari faktor-faktor lain yang dapat mempengaruhi tingkat kesadaran merek yang dapat digunakan sebagai topik penelitian kedepannya, hingga teori-teori yang dapat dijadikan acuan dalam penyusunan penelitian selanjutnya.

2. Penggunaan iklan billboard untuk meningkatkan tingkat kesadaran merek Lazada sebenarnya merupakan langkah yang baik, namun sebaiknya perlu dilakukan dengan lebih memperhatikan fungsi-fungsi dari iklan tersebut, agar ke depannya dapat lebih memberikan pengaruh yang signifikan terhadap tingkat kesadaran merek Lazada.

3. Melihat bagaimana pengaruh yang diberikan oleh promosi word of mouth terhadap tingkat kesadaran merek Lazada yang cukup signifikan, kegiatan promosi dengan mengandalkan word of mouth sebaiknya lebih diperluas, terutama dengan memanfaatkan berbagai perkembangan teknologi seperti internet dan sosial media.

\section{Ucapan Terima Kasih}

Penulis ucapkan terima kasih kepada Bapak Drs. Widayatmoko, M.M., M.Ikom selaku Dosen Pembimbing yang telah meluangkan waktunya untuk membimbing penulis hingga dapat menyelesaikan penelitian ini, serta orangtua, para responden dan juga kerabat serta sahabat penulis yang telah memberikan banyak dukungan kepada penulis. 


\section{Daftar Pustaka}

Morissan. (2010). Periklanan: Komunikasi Pemasaran Terpadu. Jakarta: Kencana Morissan. (2015). Teori Komunikasi Individu Hingga Massa. Jakarta: Kencana Sumardy. (2011). The Power of Word of Mouth Marketing. Jakarta: Gramedia Pustaka Utama

Hermawan, Agus. (2012). Komunikasi Pemasaran. Jakarta: Erlangga Sugiyono. (2011). Metode Penelitian Pendidikan. Bandung: Alfabeta Nazir, Mohammad. (2011). Metode Penelitian. Bogor: Ghalia Indonesia

Mutiara dan Febrina. (2013). Pengaruh Iklan Okezone.com di Media Cetak Terhadap Brand Awareness.

Ilmu Administrasi Niaga: Fakultas Ilmu Sosial dan Politik

http://lib.ui.ac.id/naskahringkas/2015-09/S45062-Mutiara\%20Windalita

Estherina, Vera. (2014). Hubungan Antara Terpaan Iklan Billboard Erha Clinic dengan Motivasi Pria Menggunakan Pelayanan Erha Clinic di Surabaya.

Universitas Airlangga

(http://journal.unair.ac.id/download-fullpapers-commbcb34372772full.pdf)

Mohammad Pambudi dan Ni Ketut Seminari. (2016). Pengaruh Iklan dan Word of Mouth Terhadap Brand Awareness Traveloka.

Universitas Udayana Bali: Fakultas Ekonomi dan Bisnis

https://media.neliti.com/media/publications/250770-pengaruh-iklan-dan-word-ofmouth-terhada-9f9de966.pdf

www.marketeers.com/ 